\title{
ANALISIS DATA GAS DENGAN MATHCAD : PENETAPAN PERSAMAAN KEADAAN DENGAN FITTING PARAMATER
}

\author{
Parsaoran Siahaan \\ Laboratorium Kimia Fisik, Jurusan Kimia FMIPA UNDIP Semarang
}

\begin{abstract}
Abstrak
Analisis data adalah salah satu tahap penting dalam penelitian kimia. Kesalahan dalam menganalisis data akan menyebabkan kebingungan dalam menjawab hipotesa, permasalahan dan tujuan penelitian. Kesalahan analisis data akan menghasilkan kesimpulan yang salah. Kesalahan dalam menarik kesimpulan berarti kesalahan dalam menjelaskan suatu sistem. Hasil-hasil penelitian tentang perilaku sistem gas menunjukkan bahwa gas dapat dikelompokkan dalam dua bagian yaitu gas ideal dan gas nyata. Gas ideal mengikuti hukum gas ideal $P V=n R T$ dengan harga tetapan $\mathrm{R}$ adalah $0,0821 \mathrm{~L}$ atm $\mathrm{K}^{-1} \mathrm{~mol}^{-1}$. Sedangkan gas nyata mengikuti salah satu hukum gas nyata yaitu persamaan van der Waals $\left(P+\frac{a n^{2}}{V^{2}}\right)(V-n b)=n R T$. Dari hasil
\end{abstract} analisis data suatu gas dengan Mathcad diperoleh bahwa bila gas diasumsikan mengikuti hukum gas ideal maka fitting terbaik terjadi bila harga $\mathrm{R}$ adalah $0,076 \mathrm{~L} \cdot \mathrm{atm} \cdot \mathrm{K}^{-1} \mathrm{~mol}^{-1}$ dengan standar deviasi terkecil $\sigma(R)$ adalah 0,993 .

Kata Kunci : Mathcad, Fitting, Persamaan Keadaan Gas

\section{ANALYSIS OF GAS DATA BY USING MATHCAD : DETERMINING OF STATE OF EQUATION BY PAREMETER FITTING}

\section{Abstract}

Analysis of data is a cruisal step in chemistry research. The purpose of most research is to asses relationships among a set of variables. Research may be classified brodly into three types eksperimental, quasi-eksperimental or observational. Multivariable techniques are concerned with the statistical analysis of such relationship. These technques are aplicable to all such types of research. Eksperiments are the most controlled type of study. They maximize the investigator's ability to isolate the observed effect of the predictors (independent variable) from the distorting effect of others (independent) variables that might be related to the response. To asses a relationship between two variable, one must measure both of them in some manner. Measurement inherenly and unavoidablby involves error. To make a mistake in analysis of data caused misinterpretation of hypothesis, construction of problems and objective of research. Findly, it will result in the misconclusion. The need for statistical analysis emanates from the presence of such error. The behavior of gas are classified in two types : ideal and real gas. Result of analysis of a gas data statistically by using software of Matchad give the best fitting if $\mathrm{R}$ is $0,076 \mathrm{~L} \cdot \mathrm{atm} \cdot \mathrm{K}^{-1} \cdot \mathrm{mol}^{-1}$ with deviation standard $\sigma(R)$ is 0,993 .

\section{PENDAHULUAN}

Bagaimana menetapkan apakah suatu gas mengikuti persamaan keadaan gas ideal atau gas nyata? Apakah suatu gas dapat ditetapkan mengikuti persamaan keadaan gas ideal dengan harga $\mathrm{R}$ yang berbeda dari 0,0821 L.atm. $\mathrm{K}^{-1} \cdot \mathrm{mol}^{-1}$ ? 
Apakah harga 0,0821 L.atm. $\mathrm{K}^{-1} \cdot \mathrm{mol}^{-1}$ adalah yang terbaik ? Kita seringkali menggunakan persamaan dan data tanpa pertanyaan seperti ini, sehingga kita langsung menggunakan salah satu persamaan tersebut untuk menggambarkan suatu sistem gas dan melakukan perhitungan-perhitungan dengannya. Buku yang ada jarang atau sama sekali tidak pernah menyebutkan standar deviasi konstanta R, a, dan b. Selanjutnya, tidak ada uraian yang jelas dari mana konstanta ini berasal, yaitu bagaimana proses menentukannya. Tidak dijelaskan apakah konstanta ini muncul begitu saja atau ada suatu cara untuk menetapkannya yang dapat kita pelajari. Bila kita mengadakan perhitungan-perhitungan baik secara teori maupun dalam menyelesaikan masalah-masalah nyata (Real Problems) tentu akan memilih salah satu persamaan keadaan. Dengan kata lain, jika kita mempelajari suatu subjek maka kita harus memilih model yang terbaik dengan alasan yang paling tepat. Hal ini tentu tidak mudah, karena hanya sedikit atau sama sekali tidak ada saran mana dari persamaan itu yang terbaik dan bagaimana menentukannya ${ }^{(1,2,3)}$

Untuk mengatasi kesulitan ini, kita perlu menerapkan pendekatan matematik dalam menentukan suatu pilihan. Kemampuan memilih salah satu dari antara model akan menjadi suatu keahlian dasar ["fundamental skill"] yang harus dibina sejak awal. Permasalahannya sekarang adalah bagaimana menerapkan pendekatan matematik yang ada, dalah hal ini Mathcad, dalam menetapkan persamaan keadaan gas yang sesuai untuk menjelaskan keadaan suatu gas.

Tujuan dari pemikiran ini adalah untuk menetapkan persamaan keadaan gas melalui fitting parameter kurva data eksperimen dengan persamaan keadaan gas, menghitung akar rata-rata jumlah kuadrat deviasi atau standar deviasi $(\sigma)$ dari parameter R, a, dan b antara kurva keadaan gas dari data eksperimen dengan nilai yang dihitung dari persamaan model matematika yang dapat menggambarkan data eksperimen menggunakan fung si Minerr dalam Mathcad untuk menentukan fitting parameter sehingga menghasilkan kesesuaian terbaik antara parameter persamaan dan data eksperimen.

Salah satu pertimbangan pada pemilihan antara dua model matematik seperti kedua persamaan gas di atas adalah berapa tingkat kepercayaannya. Kita harus mampu mengukur pilihan kita terhadap suatu model dengan menggunakan metode statistik. Metode ini dapat menceritakan kapan sesuatu itu lebih efektif daripada yang lain atau jika perbedaan antara dua hal itu datanya berfluktuasi acak. ${ }^{(4.5)}$

Bentuk persamaan gas ideal dan persamaan van der Waals adalah sebagai berikut $^{(1,2)}$ :

$$
\begin{gathered}
P V=n R T \\
\operatorname{dan}\left(P+\frac{a^{2}}{V^{2}}\right)(V-n b)=n R T
\end{gathered}
$$

dengan harga $\mathrm{R}=0,0821 \mathrm{~L} \cdot \mathrm{atm} \cdot \mathrm{K}^{-1} \cdot \mathrm{mol}^{-1}$, dan harga tetapan a dan $b$ untuk beberapa gas adalah : 


\begin{tabular}{|c|c|c|c|}
\hline No. & Gas & $\begin{array}{c}a \\
\left(a t m ~^{2} \text { mot }^{2}\right)\end{array}$ & $\begin{array}{c}B \\
\left(\text { (mol }^{-1}\right)\end{array}$ \\
\hline 1. & $\mathrm{He}$ & 0,034 & 0,0237 \\
2. & $\mathrm{Ne}$ & 0,211 & 0,0171 \\
3. & $\mathrm{H}_{2}$ & 0,244 & 0,0266 \\
4. & $\mathrm{~N}_{2}$ & 1,39 & 0,0391 \\
5. & $\mathrm{CO}_{2}$ & 3,59 & 0,0427 \\
6. & $\mathrm{NH}_{3}$ & 4,17 & 0,0371 \\
7. & $\mathrm{H}_{2} \mathrm{O}$ & 5,46 & 0,0305 \\
\hline
\end{tabular}

Kedua persamaan gas ideal dan van der Waals di atas menunjukkan bahwa untuk data hasil eksperimen pada temperatur dan jumlah zat berapa pun berlaku hubungan nRT sama dengan PV atau $\left(P+\frac{a n^{2}}{V^{2}}\right)(V-n b)$. Bila tidak sama maka harga tetapan $\mathrm{R}$, a, dan b perlu dikoreksi setelah terlebih dahulu melalui analisis regresi linier dengan fitting parameter $R$, a dan $b$. Dengan harga parameter $R$, $a$ dan $b$ hasil fitting ini dapat dite tapkan persamaan keadaan untuk gas ter sebut. Bila hasil analisis regresi linier fitting parameter sangat jauh dari kedua persamaan garis di atas maka perlu ditetap kan persamaan keadaan gas yang baru. ${ }^{(4.5)}$

\section{METODA PENELITIAN}

Analisis data gas dilakukan pada data hasil eksperimen pengukuran tekanan gas dengan variasi jumlah mol, volume $1 \mathrm{~L}$ dan temperatur $-50^{\circ} \mathrm{C}$ dengan data seperti pada tabel-1.

Langkah-langkah menulis data dan persamaan, perhitungan dan membuat grafik, analisis data dan fitting parameter baik persamaan gas ideal maupun persamaan gas van der Waals adalah sebagai berikut :
- Fitting parameter $R \quad$ secara manual

1. Dituliskan origin $=1$ untuk menyatakan bahwa urutan pertama data adalah 1. Urutan data default adalah 0 .

2. Dituliskan data dalam matriks dengan ukuran $11 \times 2$ (baris $\times$ kolom), misalnya $M:=\left[\begin{array}{cc}0,5 & 9,04 \\ d s t & d s t\end{array}\right]$ atau $11 \times 3$ bila dituliskan nomor urut. Bila nomor urut tidak dituliskan dalam matriks, dapat dicek dengan $\mathrm{M}=$ atau $\mathrm{n}:=\operatorname{rows}(\mathrm{M})$ dan $\mathrm{n}=$.

3. Dituliskan $P:=M^{\langle 2\rangle}$ untuk memaparkan data tekanan. Angka 2 superscript adalah menyatakan kolom 2 . Bila urutan data adalah default maka superscrips adalah kolom 1.

4. Dituliskan $P:=M^{\langle 1\rangle}$ untuk memaparkan data mol. Angka 1 superscript adalah menyatakan kolom 1 . Bila urutan data adalah default maka superscrips adalah kolom 0 .

5. Dituliskan volume $\mathrm{V}:=1$, temperatur eksperimen $\mathrm{t}:=-50$, dan temperatur $\mathrm{T}:=273,15+\mathrm{t}$.

6. Dituliskan $\mathrm{i}:=1 . \mathrm{n}$ bila urutan data pertama adalah 1 , dan $\mathrm{i}:=0 . . \mathrm{n}$ bila default.

7. Dituliskan fungsi $P V_{i}:=P_{i} V$ untuk menyatakan hasil perkalian tekanan dan volume. Karena $\mathrm{V}=1$ maka dapat ditulis $P V_{i}:=P_{i}$. Untuk memaparkan hasil perkalian dituliskan $\mathrm{PV}=$

8. Dibuat grafik antara $P V_{i}$ dengan $P_{i}$. Untuk menciptakan grafik : masuk menu Graphics, pilih Create XY Plot. dilengkapi grafik dengan 
menulis pada absis yaitu $P_{i}$ dan pada ordinat yaitu $P V_{i}$.

9. Fitting pertama parameter R. Dituliskan $R:=0,0821$ sebagai perkiraan pertama. Dituliskan fungsi $n R T a_{j}:=\operatorname{mol}_{i} R T$ yaitu perkalian $\mathrm{mol}_{\mathrm{i}}, \mathrm{R}$, dan $\mathrm{T}$.

10. Dibuat grafik $n R T_{-} a_{i}$ dengan $P_{i}$.

11. Dituliskan penyimp $_{j}:=P V_{i}-n R T_{-} a_{j} \quad$ dan standar deviasi :

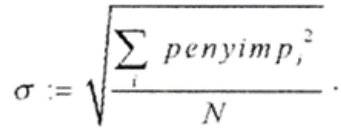

Dibuat grafik, dituliskan penyimp= dan $\sigma=$ untuk mengetahui harga.

12. Fitting kedua parameter $R$. Ditulis $R:=0,080$ sebagai perkiraan kedua.

13. Fitting secara tidak manual dengan fasilitas Minerr Mathcad langkahlangkahnya adalah sebagai berikut : dituliskan fungsi,

$F(P V, R, m o l):=\operatorname{mol} \cdot R \cdot T$, penyimp $(R):=P V-F(P V, R, m o l)$ $S S D(R):=\sum_{j=0}^{10}$ penyimp $(R)_{j}^{2}$, dan $\sigma(R):=\sqrt{\frac{S S D(R)}{N}}$.

Untuk mengecek hasil fitting nilai awal $\mathrm{R}$ misalnya $\mathrm{R}:=0,0821$ dituliskan $\operatorname{SSD}(R)=$ dan $\sigma(R)=$. Dituliskan Given $S S D(R)=0$ dan $\sigma(R)=0 \quad$ sebagai awal penyelesaian secara tidak manual dan $\quad R:=\operatorname{Minerr}(R) \quad$ untuk memperoleh fitting harga $\mathrm{R}$ terbaik. Untuk mengecek hasilnya dituliskan
$\mathrm{R}=$. Untuk mengecek de-viasi dituliskan $\operatorname{SSD}(R)=$ dan $\sigma(R)=$.

14. Setelah mendapatkan harga $R$ terbaik maka dibuat grafik hasil eksperimen, $P V_{i}$, hasil fitting pertama, $n R T_{-} a_{j}$, dan hasil fitting terbaik, $n R T_{-} b_{i}$.

\section{HASIL DAN PEMBAHASAN}

Setelah melakukan langkah-langkah pengerjaan di atas, maka diperoleh hasil sebagai berikut.

- Fitting parameter $R$ secara manual

Kurva data gas eksperimen antara PV dengan $P_{i}$ pada gambar- 1 , adalah ditunjukkan oleh garis penuh. Sedangkan kurva fitting antara $n R T$ dengan $P_{i}$ dimana fitting pertama parameter R 0,082! ditunjukkan oleh garis putus-putus. Dari gambar tersebut, dapat dilihat bahwa kurva data eksperimen menyimpang atau mengalami deviasi dari kurva fitting gas ideal dengan harga $\mathrm{R}$ adalah 0,0821 . Hasil pengolahan statistik Mathcad menunjukkan bahwa kurva data eksperimen mengalami deviasi sebesar $\sigma=5,488$. Hasil perhitungan dengan Mathcad dan kurva deviasi setiap titik data eksperimen dapat ditunjukkan pada gambar-2. Kurva hasil fitting kedua dengan harga $\mathrm{R}=0,080$ antara $\mathrm{nRT}$ dengan $\mathrm{P}_{\mathrm{l}}$, pada gambar-3, adalah ditunjukkan oleh garis putus-putus. Deviasi kurva data eksperimen dari persamaan fitting kedua dengan harga $\mathrm{R}=0,080$ adalah $\sigma=3,773$. Kurva deviasi setiap titik data eksperimen dari kurva fitting ditunjukkan gambar-4. 
- Fitting parameter $R$ secara tidak manual

Dengan menggunakan fasilitas Minerr pada Mathcad maka dapat ditentukan fitting parameter $\mathrm{R}$ ke-n hingga mendapatkan deviasi terkecil. Harga $R$ dengan deviasi terkecil $\sigma=0,993$ adalah 0,076 . Perhitungannya dapat dilihat pada gambar-5. Perbandingan kurva data eksperimen (garis penuh) dengan fitting pertama, $\mathrm{R}=0,0821$, (garis putus-putus :.....), dan fitting ke-n (garis putus-putus : $\mathrm{x} \times \mathrm{x} \times$ ) adalah seperti terlihat pada gambar-6. Perubahan harga $\mathrm{R}$, SSD, dan $\sigma$ teoritis, fitting pertama, kedua dan terbaik adalah sebagai berikut :

\begin{tabular}{|l|l|l|c|}
\hline $\begin{array}{l}\text { Fitting } \\
\text { pertama }\end{array}$ & $\mathrm{R}=0,0821$ & $\begin{array}{l}\mathrm{SS} D= \\
271,05\end{array}$ & $\begin{array}{c}\sigma= \\
5,488\end{array}$ \\
\hline $\begin{array}{l}\text { Fitting } \\
\text { pertama }\end{array}$ & $\mathrm{R}=0,0810$ & $\mathrm{SSD}=$ & $\sigma=$ \\
\hline $\begin{array}{l}\text { Fitting } \\
\text { terbaik }\end{array}$ & $\mathrm{R}=0,076$ & $\mathrm{SSD}=$ & $\sigma=$ \\
\hline
\end{tabular}

Bila harga deviasi terbaik masih dapat diperkecil dengan menggunakan asumsi bukan mengikuti persamaan gas ideal maka dapat dikatakan bahwa gas tersebut tidak mengikuti hukum gas ideal.

\section{KESIMPULAN DAN SARAN}

Dari hasil analisis data suatu gas dengan Mathcad diperoleh bahwa bila gas di-asumsikan mengikuti hukum gas ideal maka fitting terbaik terjadi bila harga $R$ adalah 0,076L.atm.K. ${ }^{-1} \mathrm{~mol}$ dengan standar deviasi $\sigma(R)$ adalah 0,993. Bila hasil analisis data gas hasil suatu eksperimen menggunakan Mathcad dengan asumsi gas nyata menunjukkan harga deviasi lebih kecil dari 0,993 maka dapat disimpulkan bahwa gas tersebut bukanlah gas ideal. Untuk itu disarankan melanjutkan analisis data dengan asumsi gas nyata misalnya menggunakan persamaan van der Waals. Fitting parameter dilakukan untuk konstanta a dan $b$ dengan harga $\mathrm{R}=0,0821$ atau dilakukan untuk ketiga konstanta.

\section{UCAPAN TERIMAKASIH}

We wish to acknowledge for several people contributed to the preparation of the paper. At first, to Prof. Dieter Ziessow, who have provided us with inspiration and professional that enabled us to gain broad experience necessary to prepare this paper.

\section{DAFTAR PUSTAKA}

1. Atkins, P. W., 1994, "Physical Chemistry", $\quad 5^{\text {th }}$. edition, Oxford University Press, Oxford.

2. Berry, R.S., Rice, S.A., Ross, J., 1980, "Physical Chemistry", John Wiley \& Sons, Inc., New York.

3. Schwenz, R.W., Moore, R.J. (editor), 1993, "Physical Chemistry : Developing a Dynamic Curriculum", American Chemical Society, Washington, DC.

4. Zdravkovski, Z., 1991, "Mathcad in Chemistry Calculations", .J. Chem. Ed, 68, A95.

5. Mathsoft, Inc., 1995, "Mathcad : User's Guide Mathcad 6.0 and Mathcad Plus $6.0^{\prime \prime}$, Mathsoft, Inc., Cambridge. 
Tabel-1 : Data Tekanan Gas dengan Variasi Jumlah Mol

\begin{tabular}{|c|c|c|c|c|c|c|c|c|c|c|c|}
\hline $\mathrm{mol}$ & 0,5 & 1 & 1,5 & 2 & 2,5 & 3 & 3,5 & 4 & 4,5 & 5 & 5,5 \\
\hline $\mathrm{P}$ & 9,04 & 17,87 & 26,5 & 34,96 & 43,28 & 51,48 & 59,58 & 67,71 & 75,59 & 83,55 & 91,54 \\
\hline$(\mathrm{atm})$ & & & & & & & & & & & \\
\hline
\end{tabular}

Gambar-1 : Kurva eksperimen dan kurva fitting pertama dengan Mathcad

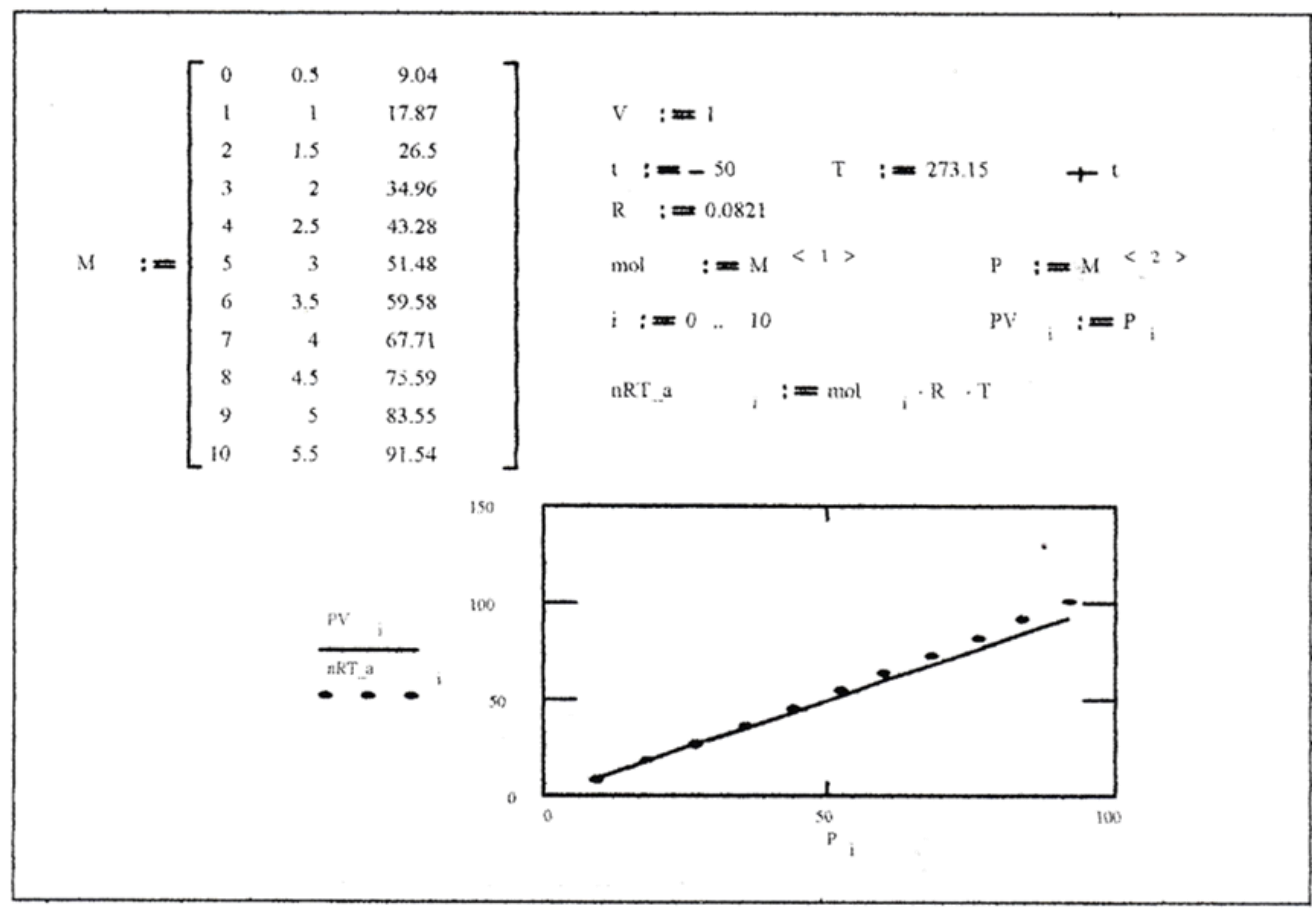


Gambar-2 : Kurva deviasi data eksperimen dari fitting pertama dengan Mathcad

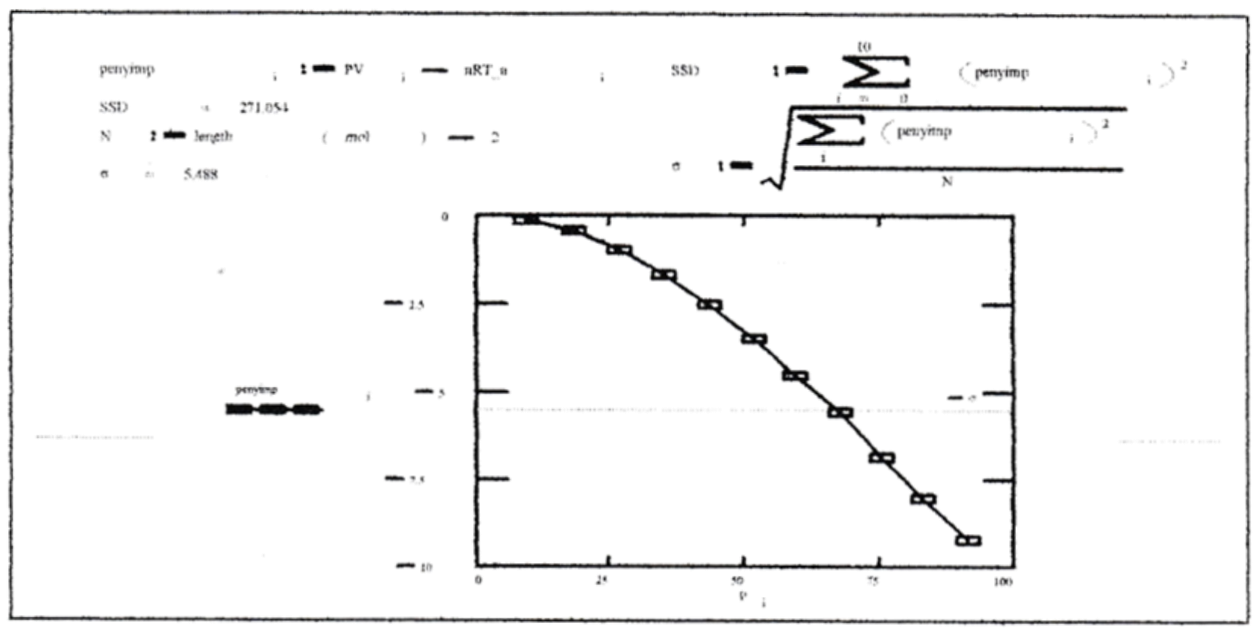

Gambar-3 : Kurva eksperimen dan kurva fitting kedua dengan Mathead

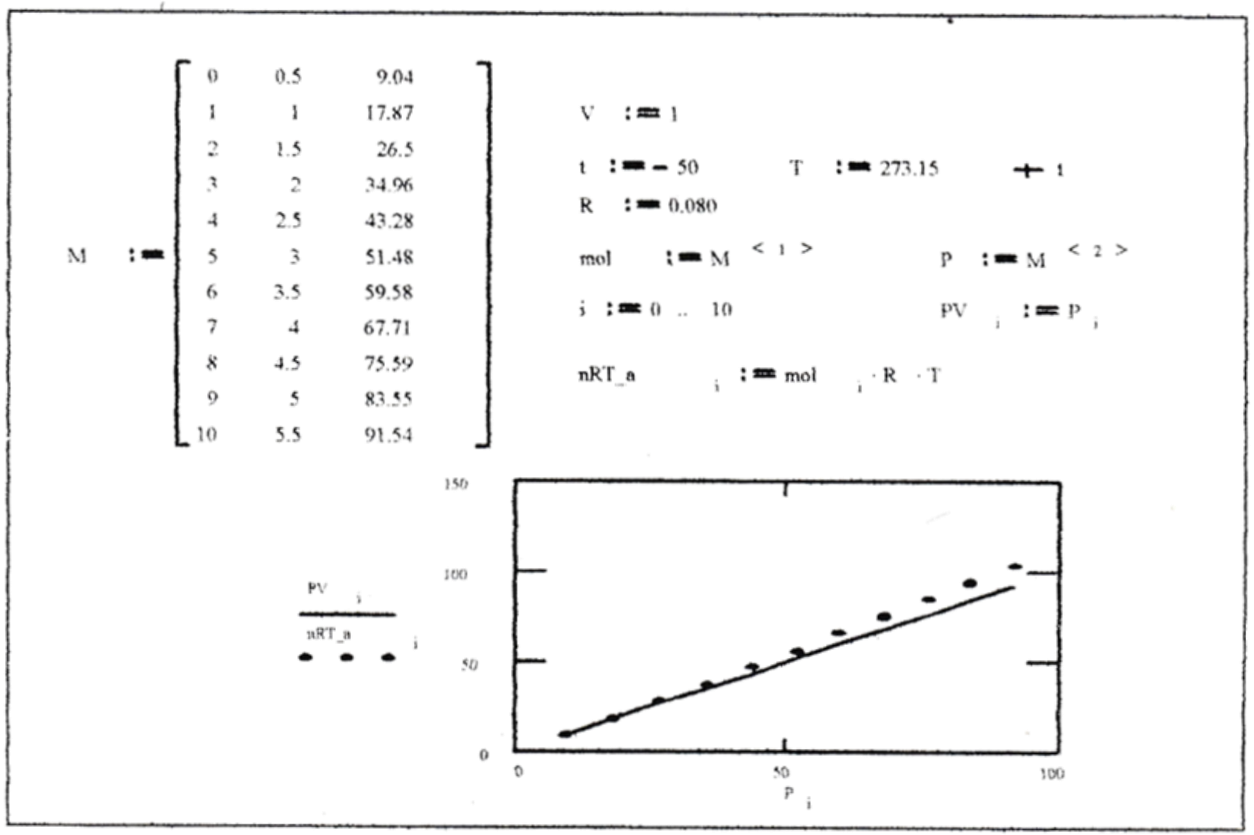


Gambar-4 : Kurva deviasi data eksperimen dari fitting kedua dengan Mathcad
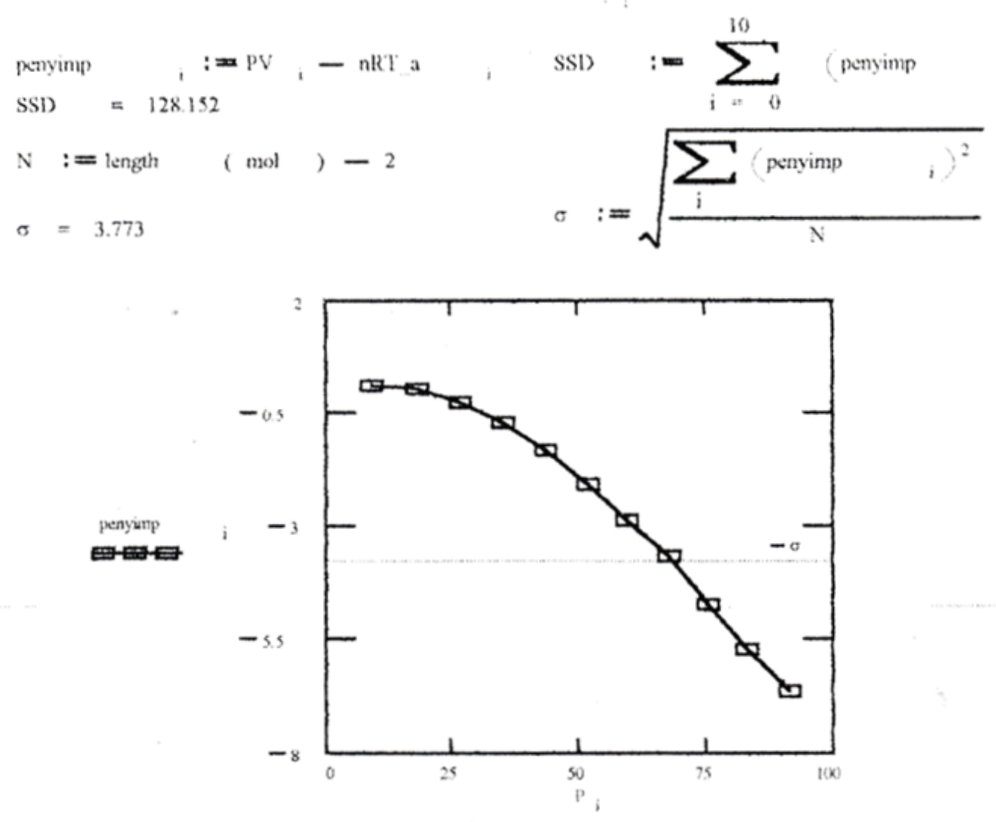

Gambar-5 : Kurva deviasi data eksperimen dari fitting ke-n dengan Mathcad

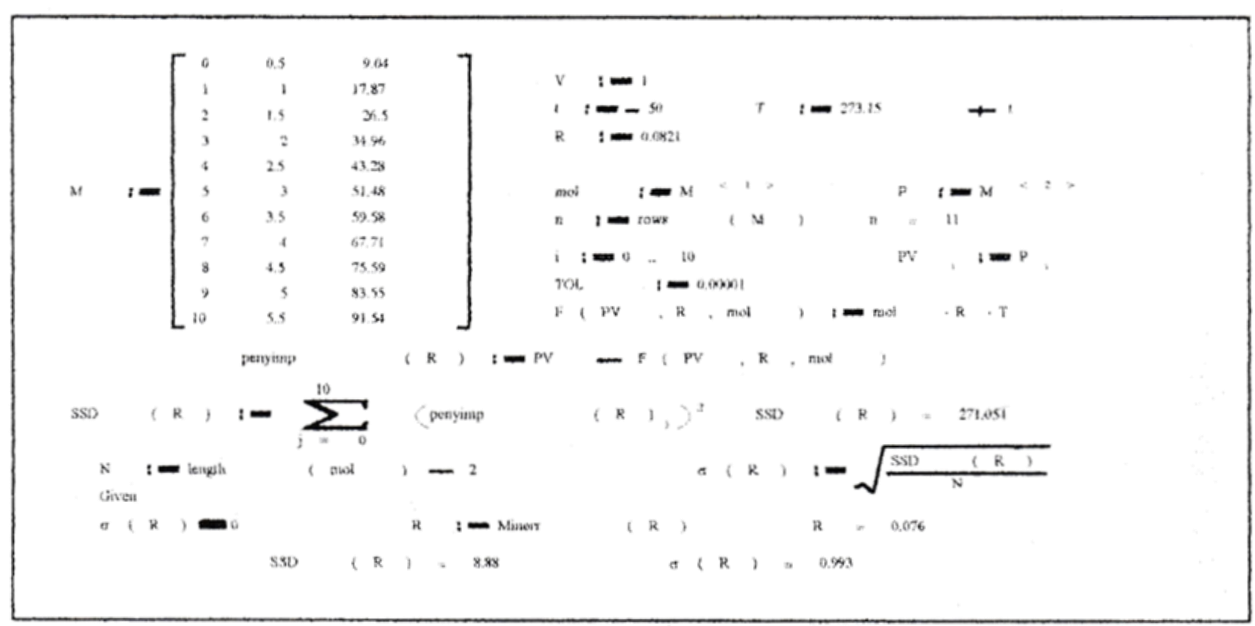


Gambar-3 : Kurva eksperimen, fitting pertama, dan fitting ke-n dengan Mathcad

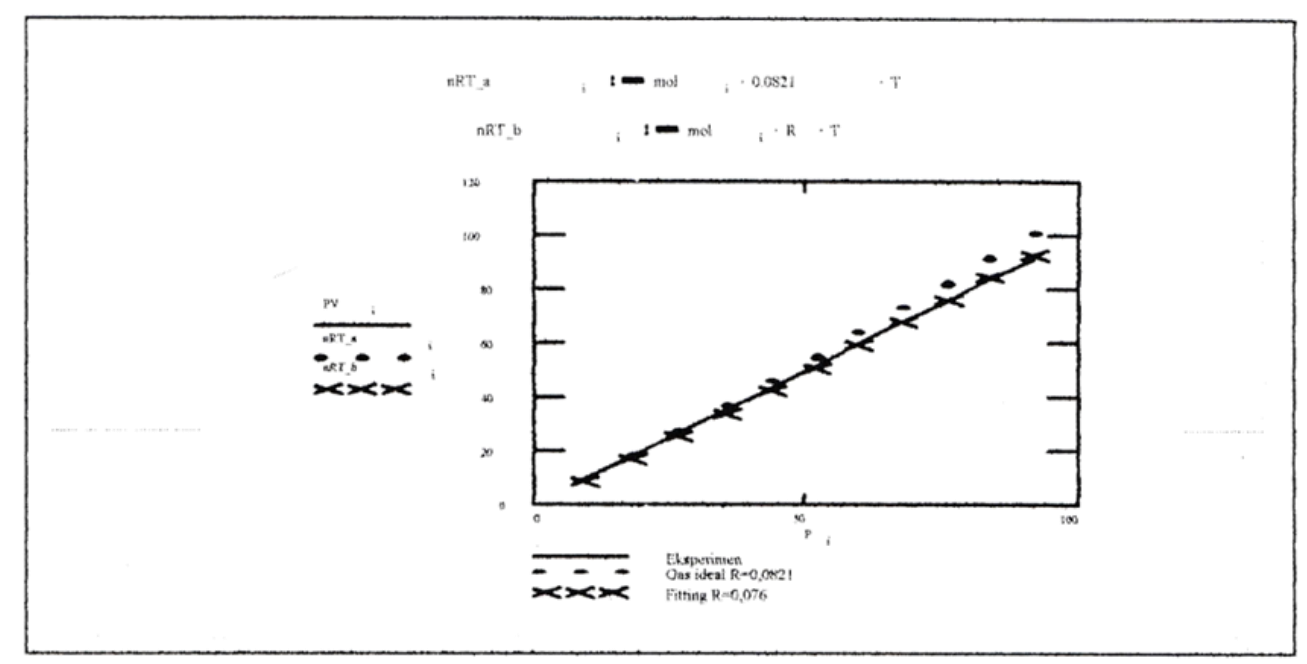

